\title{
In sickness and in health: pivotal role of vitamin D
}

\author{
Nora Nikolac Gabaj*1,2, Adriana Unic ${ }^{1}$, Marijana Miler ${ }^{1}$, Tomislav Pavicic' ${ }^{1}$, Jelena Culej ${ }^{1}$, Ivan Bolanca ${ }^{3}$, Davorka Herman Mahecic ${ }^{4}$ \\ Lara Milevoj Kopcinovic ${ }^{1}$, Alen Vrtaric ${ }^{1}$ \\ 1Department of Clinical Chemistry, Sestre milosrdnice University Hospital Center, Zagreb, Croatia \\ 2Faculty of Pharmacy and Biochemistry, University of Zagreb, Zagreb, Croatia \\ ${ }^{3}$ Department of Human Reproduction, Sestre milosrdnice University Hospital Center, Zagreb, Croatia \\ ${ }^{4}$ Department for Endocrinology, Dieabetes and Metabolism, Sestre milosrdnice University Hospital Center, Zagreb, Croatia \\ *Corresponding author: nora.nikolac@gmail.com
}

\begin{abstract}
Within the last several years, frequency of vitamin $D$ testing has multiplied substantially all over the world, since it has been shown to have an important role in many diseases and conditions. Even though liquid chromatography - tandem mass spectrometry (LC-MS/MS) has been identified as "gold standard" method for vitamin D measurement, most laboratories still use immunochemistry methods. Besides analytical problems (hydrophobicity, low circulating concentrations, ability to bind to lipids, albumins and vitamin D binding protein, presence of multiple vitamin D metabolites and variable ratios of $25(\mathrm{OH}) \mathrm{D}_{2}$ and $25(\mathrm{OH}) \mathrm{D}_{3}$ in the blood), vitamin $\mathrm{D}$ shows great preanalytical variability, since its concentration is drastically influenced by seasonal changes, exposure to sun, type of clothes or sun block creams. Vitamin D is mostly measured in serum or plasma, but new studies are showing importance of measuring vitamin D in pleural effusions, breast milk, urine, synovial fluid and saliva. Besides the main role in calcium homeostasis and bone metabolism, many studies linked vitamin D deficiency with cancer, cardiovascular diseases, diabetes, fertility and many other conditions. However, even though initial observational studies indicated that supplementation with vitamin D might be beneficial in disease development and progression; first results of well-designed randomized controlled prospective studies did not find differences in frequency of cardiovascular events or invasive cancer between patients taking vitamin D supplementation compared to placebo. In the light of these recent findings, validity of excessive vitamin $D$ testing remains an open question.
\end{abstract}

Keywords: vitamin D; preanalytical variability; diabetes mellitus; polymorphism; fertility; extravascular body fluids

\section{Introduction}

Prolific scientific activity has always been one of the main missions of the Croatian Society of Medical Biochemistry and Laboratory Medicine (CSMBLM). For more than 60 years, this society aims to educate their members on the relevant topics in the field of laboratory medicine. One of the longest continuous courses organized under the CSMBLM auspices is the annual symposium, which has been held in Zagreb in September 2019 for the 30th time. Each year, laboratory specialists, together with clinical experts from one hospital in Croatia are given the opportunity to present their knowledge on a specific topic from the fields of clinical chemistry, haematology, coagulation, immunology, toxicology or molecular diagnostics. The topic of the last symposium, organized by the Sestre milosrdnice University Hospital Center from Zagreb, was vitamin D. This paper gives an overview of the lectures presented at the symposium.

\section{Vitamin D yesterday, today, tomorrow}

In the last decade, frequency, as well as the budget for vitamin $D$ testing increased significantly worldwide (1). The explosion of vitamin D utilization is a result of many promising observational 
studies that have associated vitamin D concentration with health benefits in cardiovascular diseases, cancer, diabetes, fertility, and many others (2). The number of published papers on vitamin $D$, as well as diseases associated with its deficiency, increases daily (3).

In 2016, several professional medical societies issued Croatian national guidelines for prevention, detection and therapy of vitamin D deficiency in adults (4). Based on the cut-off values from the guidelines, vitamin $D$ concentrations lower than $30 \mathrm{nmol} / \mathrm{L}$ are considered as an extreme deficiency, $<50 \mathrm{nmol} / \mathrm{L}$ as deficiency and $<75 \mathrm{nmol} / \mathrm{L}$ as insufficiency. One should be aware that these cutoff values are not obtained on the evidence-based principle and most societies and organizations refer to the single point of origin when defining recommended vitamin D concentrations, resulting in a high number of vitamin $D$ deficient individuals (2). Recommended daily intake of vitamin $D$ for adults is $600 \mathrm{IU}$, and if sufficient amount is not ingested by food, supplements should be taken (4).

The usage of dietary supplements has become more increasing in recent years (5). A large European multicenter study published in 2018 on patient's knowledge and awareness about the effect of the over-the-counter drugs and dietary supplements on laboratory test results, has revealed some alarming issues (6). More than two thirds of patients are taking at least one dietary supplement, but they are usually not reporting the usage neither to their physicians nor to the laboratory staff. Our recent investigation has shown that immunochemistry methods for vitamin D measurement might react differently in patients taking vitamin D supplements and in patients without therapy (7). Therefore, usage of any dietary supplements should be reported to laboratory staff.

Recently however, clinical usefulness of vitamin D supplementation therapy has been questioned, since first results of well-designed randomized controlled prospective studies have been published. Surprisingly, one of the largest studies $(\mathrm{N}=$ 25,871 ) did not find differences in the frequency of cardiovascular events or invasive cancer between patients taking vitamin D supplementation com- pared to placebo (8). These findings might have long-term effects on the future of vitamin D testing.

\section{Vitamin D metabolism and mechanism of action}

Vitamin D is a fat-soluble vitamin as well as a steroid hormone precursor. There are two major forms of vitamin D: ergocalciferol $\left(D_{2}\right)$ and cholecalciferol $\left(D_{3}\right)$. About $80 \%$ of $D_{3}$ is produced by ultraviolet $B(U V B)$ irradiation of the 7-dehydrocholesterol in the skin of the most vertebrates. Vitamin $D_{2}$ is produced by UVB irradiation in plants and fungi (9). Regardless of the origin, $D_{2}$ and $D_{3}$ are biologically inactive forms before two hydroxylation processes: 1) 25-hydroxylation in the liver where they are converted to 25 -hydroxy vitamin D $(25(\mathrm{OH}) \mathrm{D})$; and 2) 1-a hydroxylation in the kidney where $D_{2}$ and $D_{3}$ are finally converted to their active form 1,25-dihydroxy vitamin $\mathrm{D}\left(1,25(\mathrm{OH})_{2} \mathrm{D}\right)$ $(9,10)$ (Figure 1). Even though the conversion of vitamin $D$ to its active form occurs primarily in the kidneys, it can also occur in the skin, prostate, brain, pancreas, adipose tissue, skeletal muscle, heart, colon, monocyte/macrophages and neoplastic tissues (11). The first step in the catabolism of active vitamin D metabolites is the 24-hydroxylation process (11). Metabolism of vitamin D is regulated by parathyroid hormone (PTH) and fibroblast growth factor 23 (FGF23) from bone osteocytes, and induces phosphaturia in the kidney via sodium phosphate $(\mathrm{NaPi}-2 \mathrm{a} / \mathrm{c})$ transporters and also suppresses 1-a-hydroxylation process, while PTH also induces phosphaturia via PTH receptor, but in contrast to FGF23, induces 1a-hydroxylase activity (Figure 1). 1,25(OH) $2 \mathrm{D}$ is responsible for the regulation of calcium and phosphate absorption from the intestine and their secretion in the kidneys while also supporting bone mineralization (12).

Vitamin D and its metabolites are transported in the circulation bound to proteins: $85 \%$ to vitamin D binding protein (VDBP) and 15\% to albumin (11). When complex reaches its target cells, vitamin D dissociates from the VDBP (or albumin), enters the cells and interacts with a nuclear vitamin $D$ receptor (VDRn). Nuclear vitamin D receptor is detected 


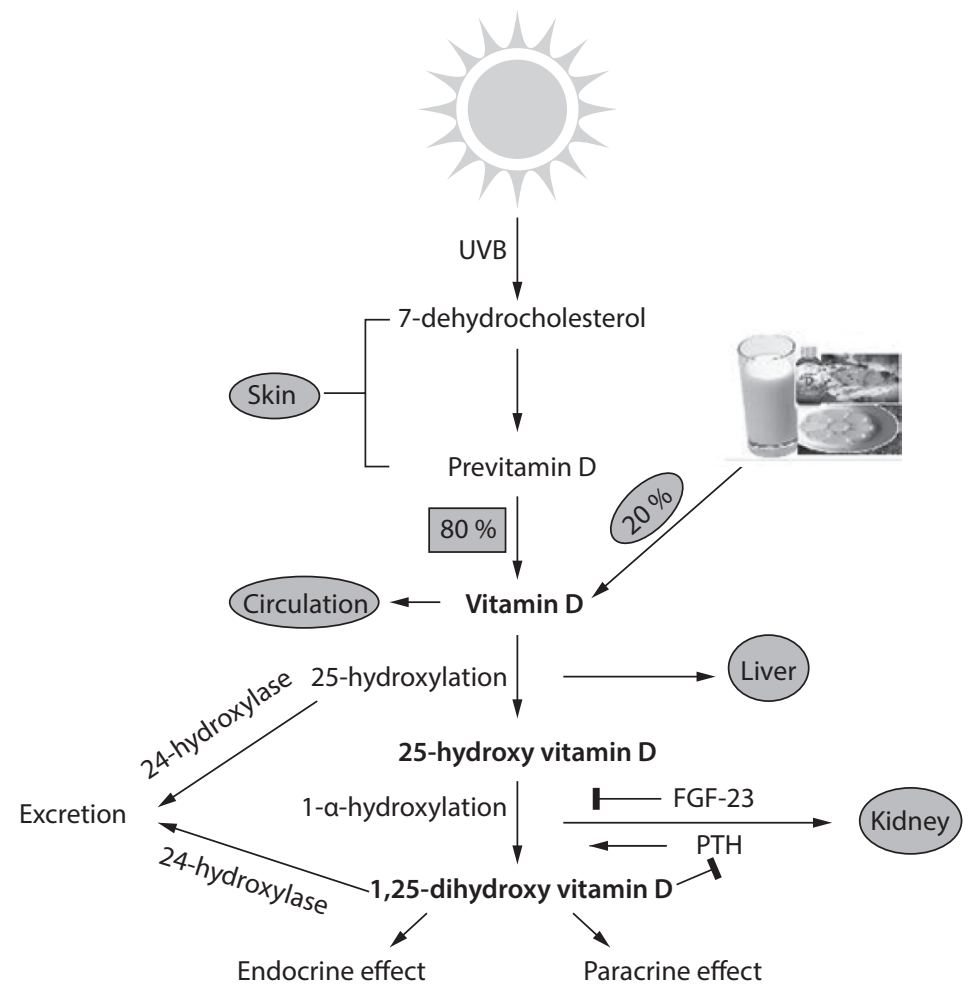

FigURE 1. Vitamin D metabolism. $80 \%$ of vitamin D is produced in the skin in response to ultraviolet B exposure and $20 \%$ of vitamin $D$ is ingested by food or supplementation. In circulation vitamin D binds to the vitamin D-binding protein and is transported to the liver, where is hydroxylated to 25-hydroxy vitamin D and then to the kidney where 1,25-dihydroxy vitamin D is formed. 1-a hydroxylation process is tightly regulated. Parathyroid hormone (PTH) stimulates while fibroblast growth factor-23 (FGF-23) and 1,25-dihydroxy vitamin D inhibit 1-a hydroxylation. Catabolism steps include 24-hydroxylation of 25-hydroxy vitamin D and 1,25-dihydroxy vitamin $D$ to 24,25 -hydroxy vitamin D and 1,24,25-hydroxy vitamin D, respectively, which are metabolized to calcitroic acid and then excreted by the kidney.

in various tissues and cells, and functions as a transcriptional factor. Liganded VDRn binds to a Retinoid-X-receptor (RXR). This heterodimeric complex can activate or suppress gene expression through binding to the elements in the promoter region of the regulated gene VDREs (vitamin D response element) initiating a formation of an assembly of nuclear transcription factors (13).

However, some effects of vitamin D in target cells are too rapid to be explained by stimulation of gene expression. It is recognized that $1,25(\mathrm{OH})_{2} \mathrm{D}$ also acts trough non-genomic actions that are mainly manifested as the activation of intracellular signaling pathways and consequently transcription factors that bind to VDREs (14). Another nongenomic action of $1,25(\mathrm{OH})_{2} \mathrm{D}$ includes the regulation of VDR binding to target receptors such as
STAT1 (signal transducer and activator of transcription 1) and IKK $\beta$ (inhibitor of nuclear factor kappa$B$ kinase subunit beta). Non-genomic effects of $1,25(\mathrm{OH})_{2} \mathrm{D}$ are mediated by membrane VDR (VDRm) (14).

The biological effects of vitamin $\mathrm{D}$ are well known. The major targets of $1,25(\mathrm{OH})_{2} \mathrm{D}$ are intestine, kidney and bones, where, together with other calciotropic hormones, maintains calcium balance (15). When concentration of serum calcium is low, $1,25(\mathrm{OH})_{2} \mathrm{D}$ acts via VDR to increase calcium absorption from the intestine. If increased intestinal absorption is not sufficient to provide normal serum concentration of calcium, $1,25(\mathrm{OH})_{2} \mathrm{D}$ and PTH, via receptors release calcium from the bone and increase reabsorption of calcium from the distal tubule of the kidney (15). 
Since the VDR expression was detected in numerous tissues it became clear that vitamin D action in many cellular targets was unrelated to mineral regulation, suggesting novel vitamin $D$ functions (16). Vitamin D novel actions that are in the focus of numerous investigations include a role in cell proliferation and differentiation, regulation of the innate and adaptive immune systems, preventive effects on neurodegenerative and cardiovascular diseases, and antiaging effects (17).

\section{Effect of preanalytical factors on vitamin D concentration}

Preanalytical factors can significantly influence vitamin D concentration and present a great source of variability. The mostly known and investigated preanalytical factors are endogenous and exogenous interferences. Based on the manufacturers' declarations, generally, vitamin $D$ is not highly sensitive to endogenous interferences of haemolysis, lipemia and icterus. However, significant differences are observed between manufacturers (Table 1).

Exogenous interferences can affect the measurement of vitamin $D$ due to the same mechanism of metabolism (cytochrome p450 for drugs) or method used (competitive or non-competitive method with streptavidin-biotin interactions for biotin). Interferences of biotin could therefore result with the concentration of vitamin D that is over or underestimated for almost 50\% (18).

Both serum and plasma can be used interchangeably for the measurement of vitamin D concentration (19). Moreover, published studies proved that vitamin D metabolite $25(\mathrm{OH}) \mathrm{D}$ is a very stable analyte in almost all storage conditions. The concentration of 25(OH)D is stable for days at room temperature, for years at $-20^{\circ} \mathrm{C}$, and even up to 4 multiple freeze-thaw cycles do not change results (20).

However, due to the characteristic pathway and metabolism of vitamin D, some specific preanalytical issues are known. Food rich in specific ingredients like fatty fish, sea food, mushrooms and fortified milk could result in increase of vitamin D concentration. Vitamin D concentration is associated with body mass index (BMI); increase of BMI for 5 $\mathrm{kg} / \mathrm{m}^{2}$ decreases vitamin $D$ concentration for 5 $\mathrm{nmol} / \mathrm{L}$. Furthermore, women are more deficient in vitamin $D$ than men $(21,22)$.

Since almost $90 \%$ of vitamin D synthesis is influenced by the sun, skin colour and type are also important preanalytical factors. According to the Fitzpatrick scale, white and pale skin types (I to IV) could produce more vitamin D in less time (10-15 minutes exposure to sun in summer), while darker skin types ( $\mathrm{V}$ and $\mathrm{VI}$ ) need more time of the sun exposure (23). Seasonal and geographical variations affect vitamin $D$ concentration with the highest

TABLE 1. Manufacturers' declarations on effect of haemolysis, lipemia and icterus on vitamin D measurement

\begin{tabular}{|c|c|c|c|c|c|c|c|}
\hline $\begin{array}{l}\text { Analyzer type } \\
\text { (manufacturer) } \\
\text { Method }\end{array}$ & $\begin{array}{l}\text { Architect } \\
\text { i2000 } \\
\text { (Abbott) } \\
\text { CMIA }\end{array}$ & $\begin{array}{c}\text { UniCel DxI } \\
\text { (Beckman Coulter) } \\
\text { Reagent Diazyme } \\
\text { Immunoturbidimetry }\end{array}$ & $\begin{array}{l}\text { Liaison } \\
\text { (DiaSorin) } \\
\text { CLIA }\end{array}$ & $\begin{array}{l}\text { CL-1000i } \\
\text { (Mindray) } \\
\text { CLIA }\end{array}$ & $\begin{array}{c}\text { Elecsys } \\
\text { (Roche) } \\
\text { ECLIA }\end{array}$ & $\begin{array}{c}\text { ADVIA } \\
\text { Centaur } \\
\text { (Siemens) } \\
\text { CLIA }\end{array}$ & $\begin{array}{c}\text { HPLC, } \\
\text { LC-MS/MS } \\
\text { (various } \\
\text { manufacturers) }\end{array}$ \\
\hline $\begin{array}{l}\text { Haemolysis } \\
\text { (g/L free Hb) }\end{array}$ & 5 & 6 & 2 & 5 & 2 & 1.25 & 5 \\
\hline $\begin{array}{l}\text { Icterus } \\
\text { ( } \mu \mathrm{mol} / \mathrm{L} \text { bilirubin) }\end{array}$ & 513 & 684 & 684 & 342 & 1128.6 & 800 & 500 \\
\hline $\begin{array}{l}\text { Lipemia } \\
\text { (mmol/L of } \\
\text { triglycerides) }\end{array}$ & 5.65 & 11.3 & 6.7 & 17 & 3.39 & 2.8 & 17 \\
\hline
\end{tabular}

Cut-off values of free $\mathrm{Hb}$, bilirubin and triglycerides above which there is significant influence of haemolysis, icterus and lipemia are presented for most commonly used manufacturers of immunochemistry methods. $\mathrm{Hb}$ - haemoglobin. CMIA - chemiluminescent microparticle immunoassay. CLIA - chemiluminescence immunoassay. ECLIA - electro-chemiluminescence immunoassay. HPLC high-performance liquid chromatography. LC-MS/MS - liquid chromatography - tandem mass spectrometry. 
concentrations measured at latitude 40 . Vitamin D concentration is lowest in winter months, and highest in autumn months after prolonged sun exposure during the summer (Figure 2).

Also, one should be aware that immigration of the population could affect the interpretation of results $(24,25)$. Furthermore, type of clothing coverage influences vitamin $D$ synthesis with a significantly lower concentration in covered females (26).
Cream with sun protection factor (SPF) above 8 blocks the synthesis of vitamin D so it is not recommended to protect the entire body surface, especially not with the highest SPF (50+) (27).

It is very important to be aware of all of the mentioned, and some others, preanalytical factors that could affect the interpretation of results and lead to possible misdiagnosis of vitamin D deficiency.

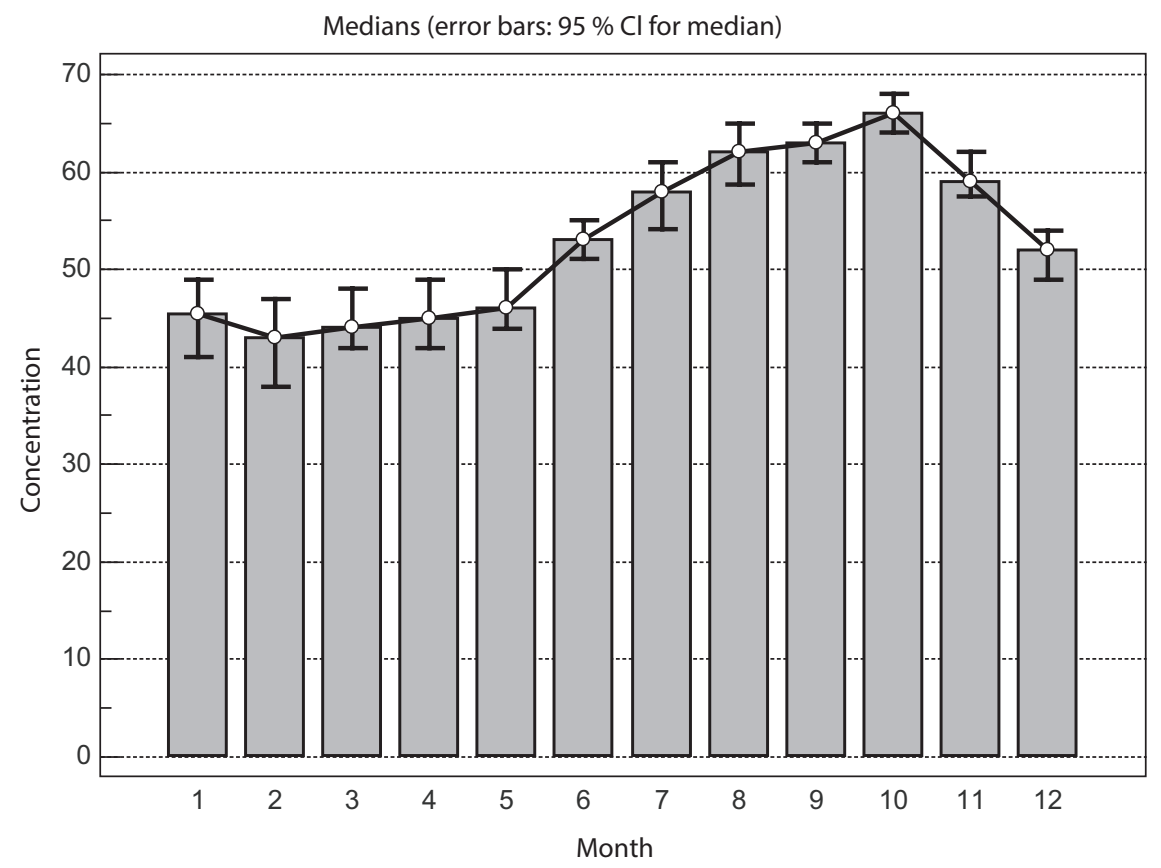

Figure 2. Seasonal differences in vitamin D concentration. Distribution of vitamin D concentrations measured in the outpatient unit of the Department of Clinical Chemistry, Sestre milosrdnice University Hospital Center, Zagreb, Croatia in 2018 (N = 5053). Bars are presenting median values with corresponding $95 \%$ confidence intervals. Unpublished data. $\mathrm{Cl}$ - confidence interval.

\section{Analytical challenges in determining vitamin D}

The general acceptance of serum total $25(\mathrm{OH}) \mathrm{D}$ (both forms, $25(\mathrm{OH}) \mathrm{D}_{2}$ and $25(\mathrm{OH}) \mathrm{D}_{3}$ ) as the best biomarker for evaluating individual's vitamin D status and assessing body's vitamin D reserves has resulted in the development of several specific and sensitive commercial assays over the past 20 years $(28,29)$. Its hydrophobicity, low circulating concentrations, ability to bind to lipids, albumins and VDBP, presence of multiple vitamin D metabo- lites and variable ratios of $25(\mathrm{OH}) \mathrm{D}_{2}$ and $25(\mathrm{OH}) \mathrm{D}_{3}$ in the circulation have defined 25(OH)D as a "difficult analyte" (30-32). Precise and accurate measurement of $25(\mathrm{OH}) \mathrm{D}$ concentration is challenging, since large differences are observed between methods. Variations between methods can be explained by: differences in vitamin D extraction, deproteinization and purification, cross-reactivity of antibodies with epimers, and/or metabolites and 
presence of matrix interferences $(33,34)$. Importantly, problems in accuracy will generally lead to systematic errors and thus may cause variability of results between different measurement techniques.

Methodologies for 25(OH)D determination include high performance liquid chromatography (HPLC) with ultraviolet (UV) detection, liquid chromatography-mass spectrometry (LC-MS) or tandem mass spectrometry (LC-MS/MS) and immunochemistry, such as enzyme immunoassays (EIA, ELISA), chemiluminescent immunoassays (CLIA, ECLIA, CMIA), radioimmunoassay (RIA) or competitive proteinbinding assays (CPB). Even though some analytical issues are present in all methods listed above, the current gold standard for $25(\mathrm{OH}) \mathrm{D}$ testing is isotope-dilution LC-MS/MS (35-37).

Despite this, automated immunoassays are responsible for $90 \%$ of routine $25(\mathrm{OH}) \mathrm{D}$ testing because of their high throughput, automated sample handling, and minimal manual work (38). Generally, techniques that are based on chromatography are more accurate than immunochemistry assays. Regarding the methods mentioned above, the separation of interfering and co-eluting C3epimers and isobars (e.g. 7-a-hydroxy-4-cholesten3-one, an endogenous bile acid precursor and 1a-hydroxy vitamin D3, an exogenous pharmaceutical compound) from the target analyte is essential, because they can overlap chromatographically with $25(\mathrm{OH}) \mathrm{D}_{3}$ or internal standard peaks and exhibit identical mass spectra, thus resulting with the positive bias when $25(\mathrm{OH}) \mathrm{D}$ is measured (39). This problem can be resolved by chiral phase high resolution chromatographic separation (40). Crossreactivity with vitamin $D$ metabolites is the main reason for large differences among different immunoassays, as well as between immunoassays and chromatography-based methods $(31,41)$. Immunoassays do not detect 3-epi-25(OH) $\mathrm{D}_{3}$. However, small antigenic molecules like $25(\mathrm{OH}) \mathrm{D}$ are challenging target for the production of specific antibodies which commonly react with $24,25(\mathrm{OH})_{2} \mathrm{D}_{3}$ and other vitamin $\mathrm{D}$ metabolites (42). All immunoassays should measure $D_{2}$ and $D_{3}$ metabolites equally (with equimolar reactivity), but detection of $25(\mathrm{OH}) \mathrm{D}_{2}$ and $25(\mathrm{OH}) \mathrm{D}_{3}$ predominantly depends on the antibody specificity. Immunoassays that are able to detect $25(\mathrm{OH}) \mathrm{D}_{2}$ cannot differentiate $25(\mathrm{OH}) \mathrm{D}_{2}$ from $25(\mathrm{OH}) \mathrm{D}_{3}$ (43). Strong binding between the lipophilic 25(OH)D and VDBP creates competition with the capturing antibody in homogenous 1-step assays where the complete separation between 25(OH)D and VDBP is not achieved (44). This issue can be overcome by manual extraction to the detriment of precision. Furthermore, almost all automated immunoassays have narrow dynamic ranges and are sensitive to matrix interferences such as heterophilic antibodies. Results of immunoassays frequently either under- or overestimate $25(\mathrm{OH}) \mathrm{D}$ concentrations at the limits of the measurement range, which are often concentration ranges most important for the clinical decision $(45,46)$. Additionally, the bias between methods is magnified by differences in the standardization of each $25(\mathrm{OH}) \mathrm{D}$ assay (47). As the number of $25(\mathrm{OH}) \mathrm{D}$ methods increases, standardization and harmonization of all available methods is essential. Hopefully, these goals are going to be achieved, to some degree at least, through the Vitamin D Standardization Program (VDSP) (48).

\section{Vitamin D in extravascular body fluids}

Serum and plasma are considered as standard samples in a clinical laboratory, and they account for the majority of all the laboratory samples. However, some laboratory tests are measured in extravascular body fluids for diagnostic purposes. Vitamin $D$ or its metabolites have been measured in urine, cerebrospinal fluid, pleural, peritoneal and synovial fluid, saliva and human breast milk.

Low serum vitamin D concentration was observed in patients with chronic kidney disease and dialysis patients, possibly due to VDBP loss through kidneys, and the role of the kidneys in vitamin D metabolism (49). Urine has become a fluid of interest due to the tubular reabsorption of VDBP and excretion of vitamin D metabolites (50).

Poor vitamin D status has been associated with higher risk and poor outcome in patients with multiple sclerosis (51). Also, the neuroprotective 
action of vitamin D has been observed in Alzheimer's disease. Studies addressing vitamin D in cerebrospinal fluid are based on findings that vitamin $D$ receptors are abundantly expressed on brain tissue, the ability of $1,25(\mathrm{OH})_{2} \mathrm{D}$ synthesis in the brain, and immunomodulatory role of vitamin $D(52)$.

Vitamin $D$ concentration is investigated in the pleural and peritoneal fluid due to its immunomodulatory effect. Higher vitamin D concentrations were observed in exudate effusions which supports a theory that vitamin $D$ is moving toward the effusion due to an inflammatory process. Lower serum - ascites vitamin D gradient was observed in patients with spontaneous bacterial peritonitis (SBP) supporting vitamin D role in peritoneal fluid and immunological process $(53,54)$.

In synovial fluid, $1,25(\mathrm{OH})_{2}$ vitamin $\mathrm{D}$ has been actively synthesized and catabolized by synovial fibroblasts which were the basis for assessment of the association between vitamin D in synovial fluid and serum in patients with rheumatoid arthritis $(55,56)$. Saliva is interesting as a sample due to its availability and non-invasive collection, which is appropriate in the pediatric population (57). The nutritional value of human breast milk regarding vitamin D concentration was assessed because of previous findings that human breast milk does not fulfill the daily need for vitamin D in infants. A higher concentration of vitamin $D$ was measured in hindmilk compared to foremilk (58).

Considering multiple functions of vitamin $D$ in the immune system, its hormonal activity and regulation of calcium homeostasis, there is no doubt that investigating vitamin $D$ in extravascular body fluids could be of diagnostic importance. However, there are some considerations that should be taken into account when interpreting the results of these studies. First of all, the sample sizes of those studies are small, which doesn't surprise considering the fact that these are rare samples, and sometimes difficult to collect (cerebrospinal fluid, for example). Second, results should be interpreted considering study design, mostly case-control which does not provide strong evidence according to the hierarchy of scientific research (59). And third, the different methodology provides different possibil- ities regarding vitamin $\mathrm{D}$ concentration measurement. For instance, immunochemical tests for routine diagnostic measure 25(OH)D, which doesn't provide information on vitamin D isoforms. LC-MS/ MS and its variants enable distinction between $25(\mathrm{OH}) \mathrm{D}_{2}$ and $25(\mathrm{OH}) \mathrm{D}_{3}$, and conjugation positions of glucuronidated vitamin D. Understanding limitations of extravascular body fluids as a sample and characteristic of the method are the basis for the future study design of vitamin D in extravascular body fluids.

\section{Vitamin D and fertility}

The main role of vitamin $D$ is calcium homeostasis and bone mineralization. Since numerous human cells and tissues express VDR and the enzymes involved in its metabolism, vitamin D deficit is linked to the large number of diseases such as diabetes mellitus, cancer, autoimmune, infectious and cardiovascular diseases $(2,60)$. Among others, VDR is expressed in ovarian tissue, uterus and placenta as well (61-63).

Although results are still inconclusive, existing data suggest a possible beneficial role of vitamin $D$ in fertility. Vitamin D deficit is observed in women of reproductive age with rather high frequency, ranging from 20 to $52 \%$, as reported by some authors (64). Besides that, many studies imply that vitamin D may as well have an important role in pregnancy outcomes.

Vitamin D enzymes and receptors are detected in the endometrium and have an important role in pregnancy implantation (65). There is evidence that the deficit of vitamin D can lead to poor placentation, which can result with hypertension and foetal growth restriction (66). Initial embryo implantation is regulated by vitamin $\mathrm{D}$ and improper implantation caused by vitamin D deficiency, is the cause of poor placentation, as hypothesized by some authors $(67,68)$. Other adverse pregnancy outcomes, including preterm birth and gestational diabetes, have been observed in women with vitamin D deficiency. Additionally, vitamin D deficiency is thought to have several adverse effects on human fertility. According to the published find- 
ings, vitamin D concentration correlates well with ovarian reserve markers, especially anti-Mullerian hormone $(\mathrm{AMH})$, suggesting that lower ovarian reserve in late reproductive-aged may be linked to vitamin D deficit (69).

Furthermore, vitamin D might have a beneficial effect on metabolic and hormonal parameters of polycystic ovary syndrome and endometriosis, which are one of the most common causes of female infertility. Although the exact mechanism of how vitamin D affects polycystic ovaries and endometriosis is not yet known, several explanations have been proposed.

In vitro fertilization (IVF) outcome and higher concentrations of vitamin $D$ have been positively linked in most of the published studies. Based on the recently published data, vitamin D deficiency affects pregnancy success in women undergoing day 5 single embryo transfer (SET). Vitamin D deficiency negatively effects endometrial receptivity, which was identified as the main cause of the lower clinical pregnancy rates (70-72).

Interestingly, epidemiological studies have shown variations in human reproductive capacity throughout the year, which could be explained, at least in part, by seasonal changes of vitamin $D$ concentrations (73).

In male infertility, both low and high concentrations of vitamin $D$ in serum negatively affect spermatozoa number, their progressive movement and morphology (74).

Although it is not yet established whether vitamin $D$ truly has an essential role in human fertility, the topic is worth exploring.

\section{Diabetes mellitus and vitamin D}

Renewed interest in vitamin D, the so-called "sunshine vitamin", has occurred recently because it has been linked to everything from cancer and heart disease to diabetes. However, most of the research is based on observational, epidemiological studies, which are important for generating hypotheses but do not prove causality. Because the destruction of $\beta$-cells usually begins in infancy or early childhood and continues until type 1 diabetes is diagnosed, it is intriguing in terms of the utility of vitamin $D$ in people with type 1 diabetes. Currently, evidence supports that maintaining adequate vitamin $D$ status during pregnancy, nursing, infancy, and childhood may help prevent type 1 diabetes. However, it is still unknown whether the genetics of type 1 diabetes place individuals at risk for vitamin $D$ deficiency or whether vitamin $D$ deficiency places individuals at risk for type 1 diabetes. Some studies have suggested that low vitamin $D$ concentrations might increase the odds of developing type 2 diabetes and that boosting vitamin D concentrations could prevent disease onset. Newly published studies showed no likely connection between diabetes and vitamin $\mathrm{D}$ concentrations. On the other hand, findings from other studies suggest that high-dose supplementation of vitamin D can improve glucose metabolism to help prevent the development and progression of diabetes.

Lower incidence of type 1, and maybe even type 2 diabetes mellitus, as well as better metabolic control may be achieved by appropriate vitamin D supplementation. However, the exact mechanisms and the level of protection are not clear and need further investigation.

\section{Vitamin $D$ in lung diseases}

In response to proinflammatory stimuli, immune cells (i.e. monocytes/macrophages, dendritic cells, lymphocytes) are able to locally activate vitamin D. The generated $1,25(\mathrm{OH})_{2} \mathrm{D}$ binds to VDR, which is ubiquitously expressed in all immune cells, and regulates the transcription of various genes associated with both activation of the innate immune system and inhibition of the acquired immune response $(17,75,76)$. The discovery of vitamin D immunomodulatory action together with the high prevalence of vitamin D deficiency found in patients with lung diseases of inflammatory pathogenesis (e.g. chronic obstructive pulmonary disease (COPD), asthma, tuberculosis (TB), respiratory tract infections (RTI) etc.), led to enhanced interest in investigating the potential therapeutic role of vitamin $D$ in such conditions $(77,78)$. 
Observational studies revealed that vitamin D deficiency found in COPD patients positively correlates with disease severity, is strongly associated with the pulmonary function (i.e. its faster deterioration) and underlying osteoporosis, and increases the risk of RTI and exacerbations (79-81). Although in vitro and animal studies suggest a potential role of vitamin $D$ in the pathogenesis of COPD, the therapeutic effects of vitamin D supplementation in COPD patients remain inconclusive $(76,77,82,83)$.

Vitamin $D$ deficiency found in asthma patients impairs lung function, promotes airway hyper-responsiveness and inflammation, decreases response to glucocorticoids and increases the risk of exacerbations (83-85). In contrast to in vitro and in vivo studies, which support a beneficial effect of vitamin $D$ supplementation, results from clinical trials are inconclusive. Thus, it remains unclear whether vitamin D supplementation offers a valid treatment option in asthma patients $(77,85,86)$.

The benefit of vitamin $D$ (i.e. from sun exposure and cod liver oil consumption) for TB treatment has been known before the antibiotic era. The anti-microbial activity of vitamin D on Mycobacterium tuberculosis was later experimentally confirmed $(77,78,87)$. Epidemiological studies associated vitamin $D$ deficiency with a higher risk of active TB, increased susceptibility to TB and disease progression (87). While a number of studies demonstrated clinical improvement in TB patients taking vitamin $D$ supplementation with standard TB treatment, others could not support these findings. Currently there is not enough data to define a role of vitamin $D$ in the prevention and/or treatment of TB $(77,87,88)$. Furthermore, in contrast to the discovered vitamin $D$ association with increased risk of RTI in epidemiological studies, there are just a few clinical trials evaluating the effects of vitamin D supplementation on RTI prevention and/or treatment, with inconclusive results $(77,79,84,87)$.

It is still uncertain if vitamin D deficiency has a role in the pathogenesis of lung diseases or it is merely a manifestation of the underlying disease (79). Adequate placebo-controlled interventional studies are needed to elucidate the potential causal rela- tionship as well as the therapeutic effects of vitamin $D$ supplementation in lung disease. Accordingly, vitamin D supplementation is not recommended above and beyond what is required for osteoporosis and fall prevention $(89,90)$.

\section{Vitamin D receptor polymorphisms in rheumatic diseases}

Vitamin D receptor is responsible for the biological actions of $1,25(\mathrm{OH})_{2} \mathrm{D}$. It is a steroid, intracellular receptor which consists of 427 aminoacids located on chromosome 12. The VDR gene belongs to the family of trans-acting transcriptional regulatory factors (91). It encodes the nuclear hormone receptor for vitamin $D$ and plays an important role in regulating cell differentiation and proliferation. Immunoregulatory properties of vitamin $D$ in the cells of the immune system are mediated by VDR. The main effect of vitamin $D$ in the immune system is the downregulation of the Th1-driven autoimmunity and suppression of proinflammatory cytokines, such as tumour necrosis factor a (TNF-a). Low vitamin $D$ concentrations may, among other factors, be associated with VDR polymorphisms, introducing the potential immunosuppressive role of vitamin D in rheumatic diseases $(92,93)$.

Rheumatic diseases are characterized by inflammation affecting the connecting and/or supporting structures of the body, commonly the joints, but also sometimes the tendons, bones, muscles, ligaments or even organs, and can cause loss of function in those body parts. The most common rheumatic disorder is rheumatic arthritis, which on itself covers more than 100 different disorders.

The association of over 63 polymorphisms on the $V D R$ gene and disease development in rheumatic diseases have been examined. Among these, rs2228570, rs1544410, rs7975232, and rs731236 were the most common $(93,94)$. The same polymorphisms have found to be associated with other lumbar spine pathologies (95). Expression of mRNA can be affected by changes in the 5'-promoter of the VDR gene, while sequence variations in the 3' untranslated region (UTR) can alter mRNA stability and protein translation efficiency. Howev- 
er, the changes can take place in exons also, consequently leading to changes in the protein sequence.

Methods used for polymorphism detection include: restriction fragment length polymorphisms (RFLP), DNA sequencing techniques and real time PCR with hydrolysing or hybridizing probes.

However, heterogeneity in results was found by various authors (91). Polymorphisms of VDR may be the key to understand this heterogeneity. In understanding the VDR gene polymorphism as a significant risk factor for rheumatic diseases, several facts need to be considered. Source of heterogeneity among studies might have been due to other factors, such as diversity in the population (age, ethnicity, sun exposure and dietary vitamin D intake, etc.), study design and genotyping methods. Some studies have shown that the ethnic (genetic) background, gene-gene or gene-environment interactions and lifestyle (sun exposure, dietary vitamin $D$ intake and obesity) might have a significant impact on increased risk of rheumatic diseases in association with polymorphisms (96).

\section{References}

1. Zhao S, Gardner K, Taylor W, Marks E, Goodson N. Vitamin $D$ assessment in primary care: changing patterns of testing. London J Prim Care (Abingdon). 2015;7:15-22. https://doi.or g/10.1080/17571472.2015.11493430

2. Holick MF. Vitamin D deficiency. NEngl J Med. 2007;357:26681. https://doi.org/10.1056/NEJMra070553

3. Yang A, Lv Q, Chen F, Wang D, Liu Y, Shi W. Identification of Recent Trends in Research on Vitamin D: A Quantitative and Co-Word Analysis. Med Sci Monit. 2019;25:643-55. https:// doi.org/10.12659/MSM.913026

4. Vranešić Bender D, Giljevic Z, Kusec V, Laktasic Zerjavic N, Bosnjak Pasic M, Vrdoljak $E$, et al. [Smjernice za prevenciju, prepoznavanje i liječenje nedostatka vitamina d u odraslih]. Lijec Vjesn 2016;138:121-32. (in Croatian)

5. Wawryk-Gawda E, Budzyńska B, Lis-Sochacka M, ChylińskaWrzos P, Zarobkiewicz M, Jodłowska-Jędrych B. Dietary supplements - consumer assessment based on questionnaire survey. Przegl Epidemiol. 2018;72:111-20.

6. Simundic AM, Filipi P, Vrtaric A, Miler M, Nikolac Gabaj N, Kocsis $A$, et al. Patient's knowledge and awareness about the effect of the over-the-counter (OTC) drugs and dietary supplements on laboratory test results: a survey in $18 \mathrm{Eu}$ ropean countries. Clin Chem Lab Med. 2018;57:183-94. https://doi.org/10.1515/cclm-2018-0579
In conclusion, nowadays vitamin D seems to be an inevitable laboratory test in diagnosis, management and treatment of various diseases, since; undoubtedly, many studies have found a significant association of vitamin D concentration and disease development and progression. However, many of these promising original studies were not confirmed on randomized-controlled trials that have investigated the efficiency of vitamin D supplementation. Furthermore, high sensitivity to many preanalytical factors coupled with method heterogeneity and lack of harmonization point to caution in interpretation of laboratory results. If the increased financial burden of vitamin D determination and supplementation will result in a positive impact on patients' health, remains to be seen.

\section{Potential conflict of interest:}

None declared.

7. Vrtaric A, Pavicic T, Milevoj Kopcinovic L, Miler M, Culej J, Unic $A$, et al. Vitamin $D$ results for two different immunochemistry methods are not comparable in patients without vitamin D supplementation therapy. Publication in process.

8. Manson JE, Cook NR, Lee IM, Christen W, Bassuk SS, Mora $S$, et al. Vitamin D Supplements and Prevention of Cancer and Cardiovascular Disease. N Engl J Med. 2019;380:33-44. https://doi.org/10.1056/NEJMoa1809944

9. Wang S. Epidemiology of vitamin $D$ in health and disease. Nutr Res Rev. 2009;22:188-203. https://doi.org/10.1017/ S0954422409990151

10. Pilz S, Verheyen N, Grübler MR, Tomaschitz A, März W. Vitamin $D$ and cardiovascular disease prevention. Nat Rev Cardiol. 2016;13:404-17. https://doi.org/10.1038/nrcardio.2016.73

11. Bikle D. Vitamin D: Production, Metabolism, and Mechanisms of Action. In: Feingold KR, Anawalt B, Boyce A, et al., editors. Endotext [Internet]. South Dartmouth (MA): MDText. com, Inc.; 2000. Available at: https://www.ncbi.nlm.nih.gov/ books/NBK278935/. Accessed on: August 21, 2019.

12. Blau JE, Collins MT. The PTH-Vitamin D-FGF23 axis. Rev Endocr Metab Disord. 2015;16:165-74. https://doi. org/10.1007/s11154-015-9318-z 
13. Haussler MR, Whitfield GK, Kaneko I, Haussler CA, Hsieh D, Hsieh J-C, Jurutka PW. Molecular Mechanisms of Vitamin D Action. Calcif Tissue Int. 2013;92:77-98. https://doi. org/10.1007/s00223-012-9619-0

14. Hii CS, Ferrante A. The Non-Genomic Actions of Vitamin D. Nutrients. 2016;8:135. https://doi.org/10.3390/nu8030135

15. Veldurthy V, Wei R, Oz L, Dhawan P, Jeon YH, Christakos $S$. Vitamin $D$, calcium homeostasis and aging. Bone Res. 2016;4:16041. https://doi.org/10.1038/boneres.2016.41

16. Pike JW, Meyer MB, Lee SM, Onal M, Benkusky NA. The vitamin $D$ receptor: contemporary genomic approaches reveal new basic and translational insights. J Clin Invest. 2017;127:1146-54. https://doi.org/10.1172/JCl88887

17. Gil Á, Plaza-Diaz J, Mesa MD. Vitamin D: Classic and Novel Actions. Ann Nutr Metab. 2018;72:87-95. https://doi. org/10.1159/000486536

18. Li J, Wagar EA, Meng QH. Comprehensive assessment of biotin interference in immunoassays. Clin Chim Acta. 2018;487:293-8. https://doi.org/10.1016/j.cca.2018.10.013

19. Colak A, Toprak B, Dogan N, Ustuner F. Effect of sample type, centrifugation and storage conditions on vitamin $D$ concentration. Biochem Med (Zagreb). 2013;23:321-5. https:// doi.org/10.11613/BM.2013.039

20. Wielders JPM, Wijnberg FA. Preanalytical Stability of 25(OH)-Vitamin D3 in Human Blood or Serum at Room Temperature: Solid as a Rock. Clin Chem. 2009;55:1584-5. https://doi.org/10.1373/clinchem.2008.117366

21. Lagunova Z, Porojnicu AC, Lindberg F, Hexeberg S, Moan J. The dependency of vitamin D status on body mass index, gender, age and season. Anticancer Res. 2009;29:3713-20. https://doi.org/10.14341/2071-8713-4886

22. Lagunova Z, Porojnicu AC, Grant WB, Bruland $\varnothing$, Moan JE. Obesity and increased risk of cancer: does decrease of serum 25-hydroxyvitamin $D$ level with increasing body mass index explain some of the association? Mol Nutr Food Res. 2010;54:1127-33. https://doi.org/10.1002/mnfr.200900512

23. Webb AR, Kazantzidis A, Kift RC, Farrar MD, Wilkinson J, Rhodes LE. Colour Counts: Sunlight and Skin Type as Drivers of Vitamin D Deficiency at UK Latitudes. Nutrients. 2018;10:E457. https://doi.org/10.3390/nu10040457

24. Wahl DA, Cooper C, Ebeling PR, Eggersdorfer M, Hilger J, Hoffmann K, et al. A global representation of vitamin D status in healthy populations. Arch Osteoporos. 2012;7:155-72. https://doi.org/10.1007/s11657-012-0093-0

25. Hintzpeter B, Scheidt-Nave C, Müller MJ, Schenk L, Mensink GBM. Higher Prevalence of Vitamin D Deficiency Is Associated with Immigrant Background among Children and Adolescents in Germany. J Nutr. 2008;138:1482-90. https://doi. org/10.1093/jn/138.8.1482

26. Buyukuslu N, Esin K, Hizli H, Sunal N, Yigit P, Garipagaoglu $M$. Clothing preference affects vitamin D status of young women. Nutr Res. 2014;34:688-93. https://doi.org/10.1016/j. nutres.2014.07.012

27. Wolpowitz $D$, Gilchrest BA. The vitamin $D$ questions: how much do you need and how should you get it? J Am Acad Dermatol. 2006;54:301-17. https://doi.org/10.1016/j. jaad.2005.11.1057
28. Holick MF. Vitamin D status: measurement, interpretation and clinical application. Ann Epidemiol. 2009;19:73-8. https://doi.org/10.1016/j.annepidem.2007.12.001

29. Lai JK, Lucas RM, Clements MS, Harrison SL, Banks E. Assessing vitamin D status: pitfalls for the unwary. Mol Nutr Food Res. 2010;54:1062-71. https://doi.org/10.1002/ mnfr.200900468

30. Farrell CJL, Martin S, McWhinney B, Straub I, Williams P, Herrmann M. State-of-the-art vitamin D assays: A comparison of automated immunoassays with liquid chromatography-tandem mass spectrometry methods. Clin Chem. 2012;58:53142. https://doi.org/10.1373/clinchem.2011.172155

31. Fuleihan GH, Bouillon $R$, Clarke B, Chakhtoura M, Cooper $C$, McClung $M$, et al. Serum 25-Hydroxyvitamin D levels: variability, knowledge gaps, and the concept of a desirable range. J Bone Miner Res. 2015;30:1119-33. https://doi. org/10.1002/jbmr.2536

32. Carter GD. 25-hydroxyvitamin $D:$ A difficult analyte. Clin Chem. 2012;58:486-8. https://doi.org/10.1373/ clinchem.2011.180562

33. Lanteri $P$, Lombardi G, Colombini A, Banfi G. Vitamin $D$ in exercise: Physiologic and analytical concerns. Clin Chim Acta. 2013;415:45-53. https://doi.org/10.1016/j. cca.2012.09.004

34. Jones G. Interpreting vitamin D assay results: Proceed with caution. Clin J Am Soc Nephrol. 2015;10:331-4. https://doi. org/10.2215/CJN.05490614

35. Singh RJ. Are clinical laboratories prepared for accurate testing of 25-hidroxyvitamin D? Clin Chem. 2008;54:221-3. https://doi.org/10.1373/clinchem.2007.096156

36. Tai SS, Bedner M, Phinney KW. Development of a candidate reference measurement procedure for the determination of 25-hidroxyvitamin D3 and 25-hidroxyvitamin D2 in human serum using isotope-dilution liquid chromatographytandem mass spectrometry. Anal Chem. 2010;82:1942-8. https://doi.org/10.1021/ac9026862

37. Stepman HC, Vanderroost A, Van Uytfanghe $K$, Thienpont $L M$. Candidate reference measurement procedures for serum 25-hidroxyvitamin D3 and 25-hidroxyvitamin D2 by using isotope-dilution liquid chromatography-tandem mass spectromtery. Clin Chem. 2011;57:441-8. https://doi. org/10.1373/clinchem.2010.152553

38. Galior K, Ketha $H$, Grebe S, Singh RJ. 10 years of 25-hydroxyvitamin-D testing by LC-MS/MS-trends in vitamin-D deficiency and sufficiency. Bone Rep. 2018;8:268-73. https://doi.org/10.1016/j.bonr.2018.05.003

39. Shah I, James $R$, Barker J, Petroczi A, Naughton DP. Misleading measures in Vitamin D analysis: a novel LC-MS/MS assay to account for epimers and isobars. Nutr J. 2011;10:46. https://doi.org/10.1186/1475-2891-10-46

40. Hollis BW, Horst RL. The assessment of circulating $25(\mathrm{OH})$ $D$ and 1,25(OH)2D: Where we are and where we are going. J Steroid Biochem Mol Biol. 2007;103:473-6. https://doi. org/10.1016/j.jsbmb.2006.11.004

41. Lee JH, Choi J-H, Kweon OJ, Park AJ. Discrepancy between Vitamin D Total Immunoassays due to Various Cross-reactivities. J Bone Metab. 2015;22:107-12. https://doi. org/10.11005/jbm.2015.22.3.107 
42. Coldwell RD, Trafford DJH, Makin HLJ, Varley MJ, Kirk DN. Specific estimation of 24,25-dihydroxyvitamin D in plasma by gas chromatography-mass spectrometry. Clin Chem. 1984;30:1193-8. https://doi.org/10.1093/ clinchem/30.7.1193

43. Ferrari D, Lombardi G, Giuseppe B. Concerning the vitamin $D$ reference range: pre-analytival and analytical variability of vitamin D measurement. Biochem Med (Zagreb). 2017;27:030501. https://doi.org/10.11613/BM.2017.030501

44. Heijboer AC, Blankensten MA, Kema IP, Buijs MM. Accuracy of 6 routine 25-hidroxyvitamin D assays: influence of vitamin D binding protein concentration. Clin Chem. 2012;58:5438. https://doi.org/10.1373/clinchem.2011.176545

45. Kocak FE, Ozturk B, Isiklar OO, Genc O, Unlu A, Altuntas I. A comparison between two different automated total 25-hydroxyvitamin D immunoassay methods using liquid chromatography-tandem mass spectrometry. Biochem Med (Zagreb). 2015;25:430-8. https://doi.org/10.11613/BM.2015.044

46. Holmes EW, Garbincius J, Mckenna KM. Analytical variability among methods for the measurement of 25-hydroxyvitamin D: still adding to the noise. Am J Clin Pathol. 2013;140:550-60. https://doi.org/10.1309/AJCPU2SKW1TFKSWY

47. Snellman G, Melhus $H$, Gedeborg R, Byberg L, Berglund $L$, Wernroth $L$. Determining vitamin $D$ status: a comparison between commercially available assays. PLoS One. 2010;5:e11555. https://doi.org/10.1371/journal. pone.0011555

48. Wise SA, Phinney KW, Tai SS, Camara JE, Myers GL, Durazo-Arvizu $R$, et al. Baseline assessment of 25-hidroxyvitamin $D$ assay performance: a vitamin $D$ standardization program (VDSP) interlaboratory comparison study. J Aoac Int. 2017;100:1244-52. https://doi.org/10.5740/jaoacint.17-0258

49. Tsuprykov O, Chen X, Hocher CF, Skoblo R, Lianghong Yin, Hocher $B$. Why should we measure free $25(\mathrm{OH})$ vitamin $D$ ?. J Steroid Biochem Mol Biol. 2018;180:87-104. https://doi. org/10.1016/j.jsbmb.2017.11.014

50. Kalousova M, Dusilova-Sulkova S, Zakiyanov O, Kostirova M, Safranek R, Tesar V, Zima T. Vitamin D Binding Protein Is Not Involved in Vitamin D Deficiency in Patients with Chronic Kidney Disease. Biomed Res Int. 2015;2015:492365. https://doi.org/10.1155/2015/492365

51. Holmøy T, Lossius A, Gundersen TE, Moen SM, Castellazzi M, Fainardi $E$, Casetta I. Intrathecal levels of vitamin D and IgG in multiple sclerosis. Acta Neurol Scand. 2012;125:e28-31 https://doi.org/10.1111/j.1600-0404.2011.01577.x

52. Johansson P, Almqvist EG, Johansson JO, Mattsson N, Andreasson $U$, Hansson $O$, et al. Cerebrospinal fluid (CSF) 25-hydroxyvitamin $D$ concentration and CSF acetylcholinesterase activity are reduced in patients with Alzheimer's disease. PLoS One. 2013;8:e81989. https://doi.org/10.1371/ journal.pone.0081989

53. Buonomo AR, Arcopinto M, Scotto R, Zappulo E, Pinchera B, Sanguedolce $S$, et al. The serum-ascites vitamin $D$ gradient (SADG): A novel index in spontaneous bacterial peritonitis. Clin Res Hepatol Gastroenterol. 2019;43:e57-60. https://doi. org/10.1016/j.clinre.2018.10.001
54. Amado CA, García-Unzueta MT, Fariñas MC, Santos F, Ortiz $M$, Muñoz-Cacho P, Amado JA. Vitamin D nutritional status and vitamin $D$ regulated antimicrobial peptides in serum and pleural fluid of patients with infectious and noninfectious pleural effusions. BMC Pulm Med. 2016;16:99. https:// doi.org/10.1186/s12890-016-0259-4

55. Smith SJ, Hayes ME, Selby PL, Mawer EB. Autocrine control of vitamin $D$ metabolism in synovial cells from arthritic patients. Ann Rheum Dis. 1999;58:372-8. https://doi. org/10.1136/ard.58.6.372

56. Li D, Jeffery $L E$, Jenkinson $C$, Harrison $S R$, Chun RF, Adams $J S$, et al. Serum and synovial fluid vitamin $D$ metabolites and rheumatoid arthritis. J Steroid Biochem Mol Biol. 2019;187:1-8. https://doi.org/10.1016/j.jsbmb.2018.10.008

57. Clarke MW, Black LJ, Hart PH, Jones AP, Palmer DJ, Siafarikas $A$, et al. The challenges of developing and optimising an assay to measure 25-hydroxyvitamin $D$ in saliva. J Steroid Biochem Mol Biol. 2019;194:105437. https://doi. org/10.1016/j.jsbmb.2019.105437

58. við Streym S, Højskov CS, Møller UK, Heickendorff L, Vestergaard P, Mosekilde L, Rejnmark L. Vitamin D content in human breast milk: a 9-mo follow-up study. Am J Clin Nutr. 2016;103:107-14. https://doi.org/10.3945/ajcn.115.115105

59. Petrisor B, Bhandari M. The hierarchy of evidence: Levels and grades of recommendation Indian J Orthop. 2007; 41:11-5. https://doi.org/10.4103/0019-5413.30519

60. Kassi E, Adamopoulos C, Basdra EK, Papavassiliou AG. Role of vitamin D in atherosclerosis. Circulation. 2013;128:251731. https://doi.org/10.1161/CIRCULATIONAHA.113.002654

61. Lerchbaum E, Obermayer-Pietsch B. Vitamin $D$ and fertility: a systematic review. Eur J Endocrinol. 2012;166:765-78. https://doi.org/10.1530/EJE-11-0984

62. Kinuta K, Tanaka H, Moriwake T, Aya K, Kato S, Seino Y. Vitamin Dis an important factor in estrogen biosynthesis of both female and male gonads. Endocrinology. 2000;141:131724. https://doi.org/10.1210/endo.141.4.7403

63. Halhali A, Acker GM, Garabedian M. 1,25-dihydroxyvitamin D3 induces in vivo the decidualization of rat endometrial cells. J Reprod Fertil. 1991;91:59-64. https://doi. org/10.1530/jrf.0.0910059

64. Tangpricha V, Pearce EN, Chen TC, Holick MF. Vitamin D insufficiency among free living healthy young adults. Am J Med. 2002;112:659-62. https://doi.org/10.1016/S00029343(02)01091-4

65. Lerchbaum $E$, Rabe T. Vitamin $D$ and female fertility. Curr Opin Obstet Gynecol. 2014;26:145-50. https://doi. org/10.1097/GCO.0000000000000065

66. Aghajafari F, Nagulesapillai T, Ronksley PE, Tough SC, O'Beirne M, RabiDM. Association between maternal serum 25-hydroxyvitamin D level and pregnancy and neonatal outcomes: systematic review and meta-analysis of observational studies. BMJ. 2013;346:f1 169. https://doi.org/10.1136/bmj.f1169

67. Baker AM, Haeri S, Camargo CA Jr, Espinola JA, Stuebe AM. $A$ nested case-control study of midgestation vitamin $D$ deficiency and risk of severe preeclampsia. J Clin Endocrinol Metab. 2010;95:5105-9. https://doi.org/10.1210/jc.2010-0996

68. Robinson CJ, Wagner CL, Hollis BW, Baatz JE, Johnson DD. Maternal vitamin $D$ and fetal growth in early-onset severe preeclampsia. Am J Obstet Gynecol. 2011;204:556.e1-4. https://doi.org/10.1016/j.ajog.2011.03.022 
69. Merhi ZO, Seifer DB, Weedon J, Adeyemi O, Holman S, Anastos $K$, et al. Circulating vitamin $D$ correlates with serum antimullerian hormone levels in late-reproductive-aged women: Women's interagency HIV study. Fertil Steril. 2012;98:228-34. https://doi.org/10.1016/j.fertnstert.2012.03.029

70. Garbedian K, Boggild M, Moody J, Liu KE. Effect of vitamin $D$ status on clinical pregnancy rates following in vitro fertilization. CMAJ open. 2013;1:E77-82. https://doi.org/10.9778/ cmajo.20120032

71. Paffoni A, Ferrari S, Viganò P, Pagliardini L, Papaleo E, Candiani $M$, et al. Vitamin $D$ deficiency and infertility: insights from in vitro fertilization cycles. J Clin Endocrinol Metab. 2014;99:E2372-6. https://doi.org/10.1210/jc.2014-1802

72. Polyzos NP, Anckaert E, Guzman L, Schiettecatte J, Van Landuyt $L$, Camus $M$, et al. Vitamin D deficiency and pregnancy rates in women undergoing single embryo, blastocyst stage, transfer (SET) for IVF/ICSI. Hum Reprod. 2014;29:203240. https://doi.org/10.1093/humrep/deu156

73. Rojansky N, Brzezinski A, Schenker JG. Seasonality in human reproduction: an update. Hum Reprod. 1992;7:735-45. https://doi.org/10.1093/oxfordjournals.humrep.a137729

74. Grzechocinska B, Dabrowski FA, Cyganek A, Wielgos M. The role of vitamin $D$ in impaired fertility treatment. Neuro Endocrinol Lett. 2013;34:756-62.

75. Sundar IK, Rahman I. Vitamin D and susceptibility of chronic lung diseases: role of epigenetics. Front Pharmacol. 2011;2:50. https://doi.org/10.3389/fphar.2011.00050

76. Heulens $N$, Korf $H$, Janssens W. Innate immune modulation in chronic obstructive pulmonary disease: moving closer toward vitamin D therapy. J Pharmacol Exp Ther. 2015;353:360-8. https://doi.org/10.1124/jpet.115.223032

77. Bouillon R. Vitamin D and extraskeletal health. Available at: https://www.uptodate.com/contents/vitamin-d-and-extraskeletal-health. Accessed October 19th 2019.

78. Mathyssen C, Gayan-Ramirez G, Bouillon R, Janssens W. Vitamin $D$ supplementation in respiratory diseases: evidence from randomized controlled trials. Pol Arch Intern Med. 2017;127:775-84. https://doi.org/10.20452/pamw.4134

79. Finklea JD, Grossmann RE, Tangpricha V. Vitamin $D$ and chronic lung disease: A review of molecular mechanisms and clinical studies. Adv Nutr. 2011;2:244-53. https://doi. org/10.3945/an.111.000398

80. Janssens W, Mathieu C, Boonen S, Decramer M. Vitamin $D$ deficiency and chronic obstructive pulmonary disease: a vicious circle. Vitam Horm. 2011;86:379-99. https://doi. org/10.1016/B978-0-12-386960-9.00017-4

81. Zhu M, Wang T, Wang $C$, Ji Y. The association between vitamin $D$ and COPD risk, severity, and exacerbation: an updated systematic review and meta-analysis. Int J Chron Obstruct Pulmon Dis. 2016;11:2597-607. https://doi. org/10.2147/COPD.S101382

82. García de Tena J, El Hachem Debek A, Hernández Gutiérrez $C$, Izquierdo Alonso JL. The role of vitamin D in chronic obstructive pulmonary disease, asthma and other respiratory diseases. Arch Bronconeumol. 2014;50:179-84. https://doi. org/10.1016/j.arbr.2014.03.015
83. Hejazi ME, Modarresi-Ghazani F, Entezari-Maleki T. A review of Vitamin $D$ effects on common respiratory diseases: Asthma, chronic obstructive pulmonary disease, and tuberculosis. J Res Pharm Pract. 2016;5:7-15. https://doi. org/10.4103/2279-042X.176542

84. Herr C, Greulich T, Koczulla RA, Meyer S, Zakharkina T, Branscheidt $M$, et al. The role of vitamin $D$ in pulmonary disease: COPD, asthma, infection, and cancer. Respir Res. 2011;12:31. https://doi.org/10.1186/1465-9921-12-31

85. Hall SC, Agrawal DK. Vitamin D and bronchial asthma: An overview of the last five years. Clin Ther. 2017;39:917-29. https://doi.org/10.1016/j.clinthera.2017.04.002

86. Huang H, Porpodis K, Zarogoulidis P, Domvri K, Giouleka P, Papaiwannou $A$, et al. Vitamin $D$ in asthma and future perspectives. Drug Des Devel Ther. 2013;7:1003-13. https://doi. org/10.2147/dddt.s50599

87. Hughes $D A$, Norton R. Vitamin $D$ and respiratory health. Clin Exp Immunol. 2009;158:20-5. https://doi.org/10.1111/ j.1365-2249.2009.04001.x

88. Nnoaham KE, Clarke A. Low serum vitamin D levels and tuberculosis: a systematic review and meta-analysis. Int J Epidemiol. 2008;37:113-9. https://doi.org/10.1093/ije/dym247

89. Ross AC, Manson JE, Abrams SA, Aloia JF, Brannon PM, Clinton $S K$, et al. The 2011 report on dietary reference intakes for calcium and vitamin D from the Institute of Medicine: what clinicians need to know. J Clin Endocrinol Metab. 2011;96:53-8. https://doi.org/10.1210/jc.2010-2704

90. Standing Committee of European doctors (CPME). Vitamin D nutritional policy in Europe. Available at: http://doc. cpme.eu:591/adopted/2009/CPME_AD_Brd_241009_179_ final_EN.pdf. Accessed: 19 October 2019.

91. Khoja SO, Al-Jehani RF, Bahlas SM, Algamdi SA, Attar S. Evaluation of Relationship Between Vitamin D Receptor Gene Polymorphisms and Rheumatoid Arthritis in Saudi Population. Pharmacophore. 2018;9:85-94.

92. Aslam MM, John P, Bhatti A, Jahangir S, Kamboh MI. Vitamin $D$ as a Principal Factor in Mediating Rheumatoid Arthritis-Derived Immune Response. Biomed Res Int. 2019;2019:3494937. https://doi.org/10.1155/2019/3494937

93. Mukhtar M, Sheikh N, Suqaina SK, Batool A, Fatima N, Mehmood R, Nazir S. Vitamin D Receptor Gene Polymorphism: An Important Predictor of Arthritis Development. Biomed Res Int. 2019;2019:8326246. https://doi.org/10.1155/2019/8326246

94. Tizaoui K, Hamzaoui K. Association between VDR polymorphisms and rheumatoid arthritis disease: Systematic review and updated meta-analysis of case-control studies. Immunobiology. 2015;220:807-16. https://doi.org/10.1016/j.imbio.2014.12.013

95. Colombini A, Brayda-Bruno M, Lombardi G, Croiset SJ, Ceriani C, Buligan C, et al. Bsml, Apal and Taql Polymorphisms in the Vitamin D Receptor Gene (VDR) and Association with Lumbar Spine Pathologies: An Italian Case-Control Study. PLoS One. 2016;11:e0155004. https://doi.org/10.1371/journal.pone.0155004

96. Bhanushali AA, Lajpal N, Kulkarni SS, Chavan SS, Bagadi SS, Das BR. Frequency of fokl and taql polymorphism of vitamin $D$ receptor gene in Indian population and its association with 25-hydroxyvitamin D levels. Indian J Hum Genet. 2009;15:108-13. https://doi.org/10.4103/0971-6866.60186 